\title{
Psychotherapeutische Operationsvor- und -nachsorge
}

\author{
Weniger Komplikationen, bessere Heilungschancen
}

Der medizinisch technologische Fortschritt in der Begegnung mit Krankheiten hat in den letzten Jahren rasant zugenommen. Wissenschaftler, Ärzte, Pharmafirmen sind um das Wohl der Patienten bemüht, die Aussicht auf Heilung und Gesundung auf einem nie dagewesenen Höchststand angelangt. Und dennoch gibt es zwei Antagonisten: Stress und Angst.

\section{Angst bedeutet Stress}

Eine schwere Diagnose, eine bevorstehende Operation oder eine akute Verletzung machen dem Betroffenen Angst - und Angst bedeutet Stress. Dabei handelt es sich nicht nur um seelischen, sondern auch um physischen Stress, den Schmerzen bereiten. Stress hat eine Auswirkung auf den Stoffwechsel und das gesamte Immunsystem, wirft den Gesamtorganismus aus dem Gleichgewicht. Er verzögert die Wundheilung, kann zu Komplikationen im Heilungsprozess führen und erhöht die Notwendigkeit von Medikamenten. Angst blockiert, verspannt, verringert die Schmerztoleranz. Sie löst eine Bereitstellungsreaktion an unnötiger Energie aus. Es besteht ein stringenter Zusammenhang zwischen Stressbewältigung und Heilung nach Operationen. Auch können Stress und Angst vermehrt zu Komplikationen während eines chirurgischen Eingriffes führen und zu einer längeren Verweildauer in der Intensivstation.

\section{Tumoroperationen}

\section{Stress gibt dem Krebs eine zweite Chance}

Israelische Forscher konnten nachweisen, dass die Heilungschancen nach Tumoroperationen umso größer sind, je weniger Stresshormone im Blut zirkulieren. Während und nach einem chirurgischen Eingriff muss das Immunsystem fit sein, um sich einerseits um die Heilung kümmern und andererseits um eventuell noch vorhandene Reste von Krebsgewebe attackieren zu können. Das Stress-

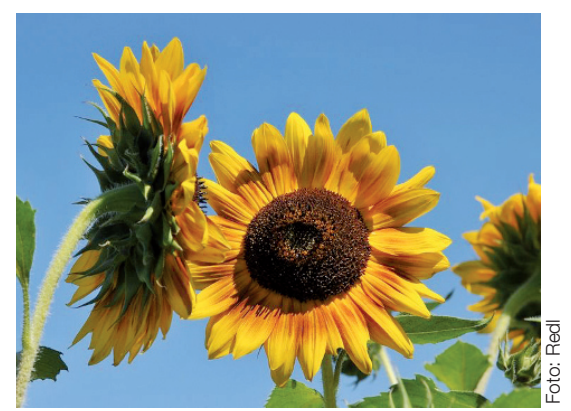

Der Prozess des Heilens vollzieht sich in allen Ebenen: der körperlichen, der emotionalen, der psychischen, der geistigen und der spirituellen.

hormon Adrenalin macht Krebszellen widerstandsfähiger und resistenter gegen Chemotherapien und gibt dem Tumor die Gelegenheit sich zu entwickeln.

Wissenschaftler setzten in einer Laborstudie Prostata- und Brustkrebszellen verschiedenen Adrenalinkonzentrationen aus. Sie konnten beobachten, dass das Stresshormon das Protein namens BAD in den Zellen ausschaltet. Dieses Protein gibt aber den Befehl zum Zellselbstmord als Reaktion auf schädliche Substanzen. Für diese Reaktion genügte schon eine Adrenalinkonzentration wie bei einer starken emotionalen Belastung oder chronischen Stressphase.

\section{Der entstresste Patient}

„Jede Affektlage begründet die Immunlage" (Viktor Frankl) ist die Basis der Psychoneuroimmunologie. Der Angst vor der Krankheit, der Unheilbarkeit, dem Ausgeliefertsein und dem Tod muss der Schrecken genommen werden. Denn eine lebensbejahende seelische Verfassung, eingebettet in den eigenen tiefen Lebenssinn und die Schicksalhaftigkeit, kann als Motivator für den Erhalt der Lebensfreude und Lebensqualität im Krankheitsgeschehen selbst, aber auch für Heilung gelten. Wer sich in ängstlicher Erwartung oder Panik befindet, hat eine negative Sichtweise, sieht wenig Lösungsmöglichkeiten, fürchtet sich vor der Zukunft und verharrt wie in einer Angststarre. Die Angst vor einer Operation ist oft so groß, dass die Patienten an ein Danach gar nicht denken. Um die Selbstheilungsmechanismen des Körpers anzuregen, bedarf es aber eines dynamischen Prozesses, der auch die Wundheilung mit einschließt.

\section{Die seelische OP-Freigabe}

Es wäre für viele Patienten eine Hilfe, wenn sie neben der medizinischen Operationsfreigabe auch eine seelische erhalten könnten. In einem therapeutischen Gespräch könnte der Patient darauf vorbereitet werden, sich einerseits von dem kranken Organ zu verabschieden, Körper-Geist und Seele auf die Operation einzustimmen und sein Denken weg von der Sorge auf Heilung zu lenken.

\section{Aktive Genesung}

Postoperativ liegen die Möglichkeiten des Patienten in seiner aktiven Teilnahme an seiner Genesung. Viele Patienten befinden sich in einer ängstlichen Erwartungshaltung, immer auf der Hut, ob sich die Krankheit, der Schmerz verschlechtert, bessert, oder der momentane Ist-Zustand erhalten werden kann. Es scheint manchmal so, als ob sie in der Zeit erstarrt wären.

Der Prozess des Heilens vollzieht sich in allen Ebenen: der körperlichen, der emotionalen, der psychischen, der geistigen und der spirituellen. Wenn Krankheit als Störung im Gesamtorganismus verstanden werden kann, dann ist Heilung ein Prozess der Selbstentdeckung, der Selbstentwicklung, die bereits weit vor der medizinischen Versorgung beginnt und auch danach nicht endet.

Eine therapeutische Begleitung und Schulung des Patienten in Stressmanagement-Techniken sollte demnach schon rechtzeitig vor dem chirurgischen Eingriff einsetzen, um ihm das nötige Rüstzeug für die Bewältigung seiner Situation sowie innere Ruhe und Vertrauen in seine Möglichkeiten zu geben. 